\title{
Emperical Data on the Correlation between CEO Duality and the Performance of a Corporate
}

\author{
Emira Spahaj \\ $\mathrm{PhD}$ Candidate \\ Faculty of Economy in Tirana, Albania \\ emiraspahaj@yahoo.com
}

\section{Abstract}

An independent CEO's discipline is greatly influenced by the way a corporate is managed, hence improving the firm's value in those corporate that are developing and the ones that have already developed. Additionally, the shareholders' interest can as well be safeguarded by the CEO and the board through creation of more safeguard guidelines. Macro-economic and microeconomic level corporate experiences significant implication from the governance, whereby corporate governance that is poor may lead to corporations' failure, for instance Worldcom and Enron experienced this type of failure. This paper scrutinizes the connection between dual and separated Chairs-CEOs structures and implications in the performance of corporate. The interest of CEO Duality emanates from the idea that CEO duality would make a difference to the performance of a firm and corporate governance. There exists controversy in the manner which the company is affected by the CEO duality. The most commonly used instruments in the implementation of corporate governance include independent directors, board size, board directors, chief executive officer, political administration, judiciary, regulatory authority and the government itself. Corporate governance also gives a specific structure via which objectives of the firm are set. Corporate governance also provides the means of accomplishing these objectives and also how to monitor the firm's performance. Corporate success and board performance does not solely depend on the chief executive's position or the position held by the chief. It does matter whether these two positions are held by one or two people. This Lack of adequate evidence in the scientific research in order to support the argument concerning separate or combined roles of a CEO, result in management dilemma. A theory supporting joint positions, is that integrating the positions of CEO and Chair minimizes the cost of transferring information which should take place if different persons hold the position of CEO and Chair. Since the transfer of information might be expensive, imperfect or untimely, having essential information reside in one joint CEO and Chair might enhance the individual's ability to carry out the responsibilities of management. In the other side a theory that supporting of split CEO and Chair positions propose that the board also carry out its supervisory duty better when the Chair is a non-executive individual. The paper aims at introducing and giving a panoramic analysis of the relevant perceptions of management and corporate governance like the CEO Duality and the implications it has in the performance of corporate. Should a CEO take action simultaneously as the Corporate Board Chairman? Would the CEO Duality hamper or improve the performance of a corporate?

Keywords; CEO, CEO duality, performance, implication on governance, Board of Directors

\subsection{PURPOSE OF THE STUDY}

Over the past couple of years, the manner in which corporate are governed has been debated by public and government especially in developed countries, and the same debate is also gaining attention in the countries that are less developed. Some of this attention includes media coverage of those employees whose allowances have been affected badly by the company officers misinforming process and those company officeholders who mislead the board of directors. The agencies concerned with regulating accounting techniques and corporate financial have improved their participation, to address these transgressions which are mostly based on public complaints.

Conflict between corporations and shareholders has been there for long. The independence or lack of corporate board of governors has been a major corporate governance topic of the past days. This independence is usually evaluated by the number of foreigner board members compared to the number of insider members with the supposition that the firm will be governed in a better manner when there are more foreign (outside members).

Nevertheless, this supposition is not supported in the research; the research arrives at diverse conclusions $(5,6$, and 7$)$.

Also, another significant concern of corporate governance is the Chief Executive Officer (CEO) compensation, which is also known as the performance incentives. Generally, greater analysis is employed by the boards in determining the 
compensation of the CEO, which include incentives, for instance the consultants' hiring compensation. In addition to greater validation of CEO compensation, a mounting group of creditors, corporate boards, investors and regulators are appealing that in case the CEOs misleads, they should return their compensation. Not only the level of board independence and the compensation of the corporate official has been regarded as important, but also extra corporate governance factors have been studied and discussed in order to enhance corporate governance. Other factors that can be included are board members age limit, interconnecting board members, the size of the board, board terms that have staggered, maximum number of boards a director may serve, directors' attendance in the board meeting, evaluations of the director, whether the CEO is a board committee's member.

\subsection{Statement of the Problem}

\section{CEO duality as a resolution to corporate governance}

CEO duality is a topic also focused by this paper. A more current presumed remedy to poor corporate governance has been the CEO duality. Chief Executive (CEO) Duality refers to the structure of an organization whereby the CEO also serves as the chairman of the same company's board of directors. Most of the firms are shifting from this structure to a separated Chair and CEO structure. This paper scrutinizes the connection between dual and separated Chairs-CEOs structures and implications in the performance of corporate.

\subsection{OBJECTIVES}

While the word "governance" is progressively more being used to draw awareness to a number of issues that influence the quality, efficiency and reach of social services, no accord has materialized on descriptions, frameworks and, in specific, how it applies in U.S., developed systems models (5). The paper aims at introducing and giving a panoramic analysis (basing on existing work from the literature of public sector and broader governance and management) of the relevant perceptions of management and corporate governance as applied to determinants of performance, Private or public sector, Board self-rule, CEO duality, Stewardship theory, Agency theory etc.

Instead of asking if a particular system has the appropriate inputs or it is producing the appropriate outputs, the questions about governance seeks at identifying the various factors that affect the behaviour of the system, such as the projected rules or procedures, sequentially to be linked with improved performance and results. The research main question reads; is there any evidence that the CEO duality hampers or improves the performance of a corporate? In this initial paper we will focus on some preliminary meanings of the term governance and exclusively converse about the CEO Board size, CEO duality and the implications on governance. (Principally applied in corporate models in the USA)

\subsection{Novelty and importance to the state of the art}

Lack of adequate evidence in the scientific research in order to support the argument concerning separate or combined roles of a CEO, result in management dilemma. Subsequently, decision-makers in an organization also lack adequate evidence to propose either structure. This paper discloses other arguments, even though they are usually unproven, general, feel good theories, supported by separatist and duality promoters by giving more objective measures of performance that emanates from duality or separated roles of a CEO.

Key shareholders and the advocates of shareholders are relentlessly pressuring corporations to separate the joint CEO/Chair roles and other firms are compelling. However, only little evidence remains to support the change of this organizational structure. Furthermore, this kind of change may create perplexity or false hopes the constituencies of corporations such as the shareholders, employees, customers and stock analyst. In the past few years, corporate governance has been scrutinized and tried but unproved improvements have been put in practice.

\subsection{Framework of Investigation}

\section{Theoretical and Empirical Framework}


Up to date, the inadequate research on duality takes two dissimilar analytical approaches: the theoretical foundation of duality or the empirical result of duality on distinct variables of performance. Legal research centres principally on theoretical ideas (such as conflicts of interests, entrenchment, and the costs of agency) to estimate the diverse structures of leadership for corporate entities. Literature in the field of financial economics, management and business, by contrast centres on the outcomes from empirical tests of distinct measures (such as compensation of the executive, stock returns and management turnover) to assess the diverse structures of corporate leadership.

Research on corporate governance comprises different variables which include the compensation of CEO, Equity ownership, performance of firm stock, board size, independence, and composition. There is comparatively less study on the correlation between CEO duality and corporate financial performance, like the return on equity, contrasted to the study that has been done on subsequent performance of company stock $(1,2)$.

The occurrence of duality in corporate calls for the significance of understanding the structure of leadership and the impact it has on the performance of a corporate. This paper evaluate s the impact of duality on the performance of a corporate via an integrated framework, by making use of legal scholarship concepts on top of data from financial, business, and management literature. This paper investigates whether combining or separating the roles of top leadership better supports the initial concept of corporate governance, by making use of these empirical results and theoretical concepts: to achieve corporate financial success, the directors are in charge for managing business operations and supervising management (3-4).

\subsection{INTRODUCTION}

There are important implications which come with corporate governance which pose on the macro and micro-economic level. Poor corporate governance can lead to the failure of many operations, as it so happened in the case of Enron and Worldcom. The most commonly used instruments in the implementation of corporate governance include independent directors, board size, board directors, chief executive officer, political administration, judiciary, regulatory authority and the government itself.

The value of an organization can be improved by the merged effort of the independent directors, the board of directors, CEO and the mangers via the good performance of the fiduciaries. The regulatory authority's together with the judiciary and government is very significant the bid to improve the value of the organisation since these three organisations can very well protect the rights of the shareholders and also put into place the corporate governance in both the developed and the developing financial markets. Corporate governance has a very important impact in terms of disciplining an independent and powerful chief executive officer. Likewise, the board, in conjunction with the CEO can safeguard the interests of the firm's shareholders through creation of more value for them.

\subsection{Governance- Definition of Private and Public Sector}

Analysis of governance can be analyzed in the widest level in terms of political actors who take part in contesting and collaboration in order to establish specific policies for the public in each and every society in the secondary level, governance can be analyzed in terms of the different categories of these particular public policies. These public policies include institutions, laws, the resultant rules and enforcement mechanisms. It can also be analyze in terms of the level of specific firms for instance the governance of the district of social security institute. According to the literature of the private corporations, it initially focused on governance in terms of the existing relationship between the mangers and the shareholders. This literature tried to find out what governs the actions of the mangers in the corporate organizations that showed increasing autonomy from the owners of their firms since the $19^{\text {th }}$ and $20^{\text {th }}$ century. As depicted from the OECD, corporate governance is a set of links between the firm's management and the board, stakeholders and shareholders. Corporate governance also gives a specific structure via which objectives of the firm are set. Corporate governance also provides the means of accomplishing these objectives and also how to monitor the firm's performance. The governing of the public sector literature also mirrors the private corporation literature. These studies herein also focus on governance as a set of links, structures of incentives and goal-setting procedures. However, the public agencies also face a number of problems since they respond to a bigger number of interest groups. This is so because when a firm answers to multiple 
groups, there is a likelihood that the ability of one group to attain its set target can be watered down and the result of the firm's performance can hence be influenced by competing principals $(7,8)$.

\subsection{Governance and CEO duality}

When the CEO operates concurrently as the chairman of the board, the corporate is said to have a dual CEO. In the literature of company strategy and corporate governance, CEO duality has received great interest (18). Much of this interest emanates from the idea that CEO duality would make a difference to the performance of a firm and corporate governance (mostly, this applies to private sectors). There exists controversy in the manner which the company is affected by the CEO duality. Interest parties that resist about CEO duality like the watchdogs of corporate governance and shareholders advocate groups proposes that CEO duality might negatively affect the performance of a firm since the structure of duality might reduce the ability of the board to govern, which is its main function.

From this argument, the following question arises; what is the role of the CEO if the board of directors is representing the stockholders' interest? Does he have a variance of interest? He is the skilled manager. He cannot fairly sit in judgement and represent the shareholders. It becomes more complex to hold the CEO of a company answerable for his/her actions if the CEO and the chairman of the board is the same person and consequently the performance of a corporate may suffer. Academics propose that CEO duality indicates the absence of division of decision control and decision management that might cause the firm to suffer in the struggle for survival. Companies like Westinghouse, IBM, Sears and General Motors has experienced poor performance due to CEO duality. While defending CEO duality, Anthony and Anderson (15) dispute that it offers "a central focal point for corporate management" with a possible lucid corporate mission and strategy. According to this point of view CEO duality provides firmness and stability to the corporate which in turn would result to superior performance of a corporate.

\subsection{METHODS}

For this paper, we have explored the grey literature which includes contacted professionals and websites and peer-reviewed journals on the field of corporate governance. In this study, only 30 participants had adequate information concerning their activities and impact in the grey literature and peer-reviewed from and primary sample of 70 .

In addition, we tried to contact the other twenty companies, and we received seven replies. Structured, open-ended surveys were dispatched to ten companies and staff associates were interviewed where feasible to match accessible information. We used purposive selection to eradicate the companies with very the business strategies from the same geographical areas and/or disease areas so as to capitalize on variation and to stress a broad range of activities, after evaluating the accumulated information on their business models.

\section{$5.0 \quad$ RESULTS}

\subsection{Arguments on Duality}

Some analysts have proposed that the pervasiveness of duality implies that a joint CEO and Chair role is the best leadership structure for large public corporate. Advocates of duality maintains that if duality is not an effective and efficient structure of governance, most public firms cannot maintain duality and carry on in the marketplace which is very competitive. Regardless of duality pervasiveness in corporate governance, not all of firms in America consider that duality is the best structure of leadership.

\subsection{Arguments Supporting Joint Positions}

A combining theme of the different arguments that support duality is that integrating the $\mathrm{CEO}$ and Chair positions improves the performance of the board management. The responsibilities of the board management call for major decisions that affect the firm. Advocates of duality argue that integrating the CEO and Chair position improves the role of the board management. They argues that a joint CEO and Chair position provides the board with a more absolute and well-timed 
information concerning the corporate, creates joint and collegial environment for board decision making and a reliable leadership direction, and provides the corporate with integrated structure of command.

Considering these arguments independently, the first speculation is that the board of directors will gain from having a Chair with deep personal knowledge of the corporate. Advocates argue that a board Chair who also functions as the Chief Executive Officer is expected to spend more time at the firm, in order to have more comprehensive information concerning the weakness and strength of the firm, and to have a deeper insight on the financial and operational health of the firm.

Most probably, the Chief Executive Officer might use the awareness and knowledge that he/she gets from operating as the top executive of a firm (18). A similar theory is that integrating the positions of CEO and Chair minimizes the cost of transferring information which should take place if different persons hold the position of CEO and Chair.

Since the transfer of information might be expensive, imperfect or untimely, having essential information reside in one joint CEO and Chair might enhance the individual's ability to carry out the responsibilities of management.

The other wide argument that supports duality is that joint position provides a unified structure of command and minimizes the cost of making decision in a company. An individual with a CEO and Chair position can apply authority and speed up the process of making and put into practice decisions for the corporate. Therefore decisions formulated by an individual who has the CEO-Chair position might be lucid, timely and more reliable than decisions made by a CEO who has to discuss and confer with a board that is led by a different Chair. Additionally, having one person occupying the position of both CEO and Chair minimizes public perplexity concerning who is in control of the firm, and makes it clear who is accountable for the performance of the firm.

Research which support of duality primarily spotlight on the probable enhancement in the role of board's management, without considering other major role of the board especially supervising the behaviour of the executive. While other advocates propose that an individual who holds the position of a CEO and Chair has an in-depth knowledge concerning the firm which is essential to successfully observe management transgression, this individual who has an intense understanding of the weaknesses and strengths of the firm might be the person who is engaging in managerial transgression.

\subsection{Arguments Supporting Split Positions}

The board's decision-making process might experience fresh insight and knowledge when a firm has a board Chair who is not an executive. A Chair who is a non-executive might provide an exclusive viewpoint which improves the performance of the board since he/she has got experiences outside the firm and hence make strategic and essential business decisions. A Chair who is a non-executive might as well make the function of board's management easy by enhancing the board to swiftly make decisions and acquire new tactics to meet the business environment that is fast changing. Advocates of a split top leadership positions usually link Compaq Computers as an example of a corporate where adopting the structure of split Chair helped the business over the tough opposition of the Company's Chief Executive Officer to implement a product that is lower-priced in order to remain competitive in the industry (18). Advocates of split CEO and Chair positions propose that the board also carry out its supervisory duty better when the Chair is a non-executive individual. The role of monitoring obliges directors to exercise oversight role over corporate managers so as identify and control managerial ineffectiveness and transgression. Therefore, duality might cause disappointment to the board when effectively monitoring and controlling executive management. When a corporate has separate individuals serving in the positions of CEO and Chair, this minimizes the agency cost since a board led by a Chair who is a non-executive is more expected to assess independently if the performance of the management as well as that of a CEO improves the interest of the shareholders.

When one person is assigned the role of a CEO and Board Chair, the directors get themselves in an uncomfortable position of assessing a person who is, at the same time, their principal on the board and the person the rely on for committee assignments and board appointments. An additional agency dispute supporting splitting of the CEO and Chair positions is that non-executive Chairs receives more incentives than CEO-Chairs perform their functions in ways that further the interests shareholder. 


\subsection{CEO Duality and Correlation to Firm Performance}

Research on CEO duality's performance outcome has chiefly relied on two different theories: stewardship theory and agency theory. The nature of CEO duality structure together with the contrasting and strong forecast that every theory makes, seems to let the researchers to discard one theory and advocate the other with one important finding. The section that follows review the broad literature which focuses on the correlation between the performance of a firm and the CEO duality, normally integrating one or both of these primary theories.

\subsection{DISCUSSION}

Empirical proof and theoretical arguments, as replicated in the metrics of non-financial and financial aspects, favours the leadership structure that splits the position of CEO and Chair of the board. Having an individual who is a non-executive, rather than an individual with both Chair and CEO position, provides a framework of governance that is better suited to the achievement of board's primary responsibilities, to oversee the operations of a business and supervise the behaviour of management for the intention of improving the shareholder's value. In addition, empirical evidence points out not only that duality relates with poor board performance and shareholder value, but as well duality's negative impact cannot be eradicated by putting more outside directors on the board or through setting a principal director.

Corporate success and board performance does not solely depend on the chief executive's position or the position held by the chief. It does matter whether these two positions are held by one or two people. Either way, large organizations are increasingly choosing an independent and separate chairperson. This transition has gained so much praise from the institutional investors and the governance advisors but it has also introduced a number of problems. Some of these problems include disagreement by the public on the issue of the chief executive officer and the independent chairperson at AIG insurer.

That disagreement ends with the resignation of the chairperson hence raising questions about the chief executive officer's integrity. Policy makers on the other hand weigh whether it is suitable to authorize an independent and separate chairman in all United States organizations. In the CEO duality literature it is stated that the separation of the chief executive officer and the chairpersons of the board does not improve a firm's performance independently. It has also been proven that implications of the performance of the CEO duality are party to an array of certain factors. Therefore, boards should be granted the freedom to choose the type of structure which they consider to be the most beneficial to their firms. The conclusion from this discussion is that the structure of the non-executive chair is much better compared to the CEO-chair duality structure in terms of fulfilling responsibilities of the directors and improving the value of the shareholders.

Lack of assurance that splitting the two roles will provide financial and governance benefits to all firms proposes that may be this structure of leadership should not be obliged on all firms. In private companies that are smaller and where the Chairs and CEO is the majority shareholder, or they are in charge of directing the shareholders, there is effectively no division of ownership and control, there is minimal agency cost. Splitting the leadership roles of the executive and board in such firms is expected to improve performance of the board or improve the interest of the shareholder. Therefore, for larger and public companies, we make the conclusion that firms should split the positions of CEO and Chair of the board.

\subsection{CONCLUSION}

Much financial and non-financials' empirical facts on both the impact of duality supports the separation of the CEO and Chair positions. Even though the research uses diverse measures of corporate performance other researches focusing only on large firms or specific industries, and some studies using no control for other variables of governance, when observed jointly, they offer a realistic case that splitting the positions of CEO and Chair has a helpful impact on the performance of a corporate from the perspectives of financial and nonfinancial metrics.

\subsection{IMPLICATIONS AND FUTURE RESEARCH ON THE FIELD}

SEE nations should understand the USA models carefully spotlighting on the multi-dimensions of a corporate success. Using an independent evaluation must be obligatory for any material issuance of shares for assets, squeeze-outs, major 
transactions and associated party operations so as to warrant a more just treatment of every shareholder. Qualified experts who are independent should be hired to carry out such evaluations.

\section{References}

[1] Richard Harrison, David L. Torres \& Sal Kukalis, The Changing of the Guard: Turnover and Structural Change in the Top-Management Positions, 33 ADMIN. SCI. Q. 211, 211, $221-23$ (1988)

[2] Baliga B., Charles R. \& Ramesh S., CEO Duality and the performance of a corporate: What's the argument?, 17 STRATEGIC Management. J. 41, 42 (1996)

[3] See Joel Seligman, No One Can Serve Two Masters: Corporate and Securities Law After Enron, 80 WASH. U. L.Q. 449, 457-62 (2002)

[4] Sanjai Bhagat \& Bernard Black, The Uncertain Relationship Between Board Composition and Firm Performance, 54 BUS. LAW. 921, 924, 942 (1999);

[5] James P. Walsh \& James K. Seward, On the Efficiency of Internal and External Corporate Control Mechanisms, 15 ACAD. MGMT. REV. 421, 433 (1990);

[6] Dan R. Dalton \& Idalene F. Kesner, Composition and CEO Duality in Boards of Directors: An International Perspective, 18 J. INT'L BUS. STUD. 33, 39 (1987)

[7] Christopher Caggiano, Call Grows for Separation of CEO and Chairman Roles, 231 N.Y. L.J. 5 , 5 (2004);

[8] Dawn Harris \& Helfat E., CEO Duality, Succession, abilities and Agency Theory: Remarks and Study Agenda, 19 STRATEGIC MGMT. J. 901, 903 (1998).

[9] Dalton, D.R., and I.F. Kesner, 1987, Composition and CEO duality in boards of directors: an international perspective, Journal of International Business, 18, 3, 33-42.

[10] Vance, S.C., 1978, corporate governance: assessing corporate performance by boardroom attributes, Journal of Business Research, 6, 203-220.

[11] Zahra, S. and J.A. Pearce, II, 1989, Boards of directors and corporate financial performance: a review and integrative model, Journal of Management, 15, 2, 291-334.Vol.

[12] Rechner, P.L. and D.R. Dalton, 1988, Board composition and organizational performance: a longitudinal assessment, Paper presented to the Academy of Management, Anaheim, 1988.

[13] Barney, J.B., 1990, The debate between traditional management theory and organizational economics: substantive differences or intergroup conflict? Academy of Management Review, 15, 382-393.

[14] Young, G., Y. Stedham, and R. Beekun (2000) "Boards of Directors and the Adoption of a CEO Performance Evaluation Process: Agency and Institutional Theory Perspectives," Journal of Management Stud es, 37:2, pages 277-295

[15] Anderson, C.A. and R. N. Anthony, The New Corporate Directors, New York: John Wiley and Sons, 1986.).

[16] Fama, E.F. and M. C. Jensen, "Agency Problems and Residual Claims," Journal of Law and Economics, 1983, Vol. XXV1, pp. 327-349.)

[17] White, J.W. and P. Ingrassia, "Board Ousts Managers at GM; Takes Control of Crucial Committee," The Wall Street Journal, April 7, pp. A1, A8.

[18] Balsam \& Upadhyay, supra note 25, at 39 Identifying the distribution of leadership structure. Leadership 